\title{
PRINCIPAIS ATRIBUIÇOES SUPERVISOR EDUCACIONAL NA GESTÃO DEMOCRÁTICA DA ESCOLA
}

\author{
Karla Suely Brasil da Silva ${ }^{1}$ \\ Vanderleia Fernandes Barbosa ${ }^{2}$ \\ Regina Mara Candida dos Santos ${ }^{3}$ \\ Francisco Silva Gomes ${ }^{4}$ \\ Thiago dos Santos Nobre 5 \\ Severino Diego da Silva ${ }^{6}$
}

\begin{abstract}
RESUMO: O supervisor escolar é o profissional com habilitação em Pedagogia e/ou a nível de especialização, que executa serviços de supervisão e parceria pedagógica na escola, por isso é importante fomentar a importância desse profissional e seu papel na escola. O supervisor, tem o papel de atuar como o harmonizador do espaço escolar, uma vez este profissional não atua de forma isolada, tampouco como fiscal do professor, mas sim como um facilitador do trabalho pedagógico. Portanto o orientador escolar, atua como parceiro do supervisor educacional, na construção e desenvolvimento social e cultural do aluno, além de auxiliar os professores na mediação da aprendizagem ou nas dificuldades na aquisição de saber. O Serviço de Orientação Escolar é muito importante para as escolas, pois trata-se, de um profissional que tem o papel de mediar a relação entre professor, aluno, a família e a escola, além de ter papel fundamental na superação das dificuldades de aprendizagem apresentada pelos alunos no espaço escolar.
\end{abstract}

Palavras- chave: Gestão Democrática. Supervisão. Orientação. Professor. Parceria.

\section{INTRODUÇÃO}

O presente artigo fomenta considerações relevantes acerca da Gestão Escolar Democrática, como um elemento integrador do sistema de ensino e que tem a responsabilidade de gerir e administrar a escola, através da tomada de decisões, queafetam a organização e o andamento da escola.

Essa pesquisa aponta o papel do supervisor educacional na escola, e ressaltacomo o supervisor pode atuar ao lado do gestor escolar e do professor, como um parceiro

\footnotetext{
${ }^{\mathrm{I}}$ Formada em Pedagogia pela Universidade Federal do Piauí. E- mail: karlabrasil@msm.com.

${ }^{2}$ Formada em Pedagogia pela Univeridade Estadual do Goias. E-mail: vanderleiabarbosai23@hotmail.com.

${ }^{3}$ Formada em Pedagogia com Habilitação em Supervisão Escolar e Orientação Educacional pela Universidade Federal do Amapá. E-mail: reginamara722@gmail.com.

${ }^{4}$ Licenciado em Pedagogia pela Universidade Estadual do Piauí. E-mail: gomesfsil@gmail.com

5 Formado em Análise e Desenvolvimento de Sistemas pelo Instituto Federal de Rondônia. E- mail: tsnobre9o@gmail.com.

${ }^{6}$ Formado em Ciencias Biologica pela Universidade Estadual do Vale do Acaraú Campus Olinda PE. E-mail: diegopfbio87@hotmail.com
} 
indispensável na equipe pedagógica e administrativa da escola.

Esse estudo, elucida ainda, sobre as contribuições da orientação escolar na escola, como o profissional de apoio para a superação das dificuldades de aprendizagem do aluno no contexto escolar.

Essa pesquisa é de grande relevância para a comunidade acadêmica que obtiver acesso a mesma, uma vez que a discussão proposta aqui, apresenta o papel e as contribuições dos principais profissionais que atuam como parceiros do professor, dos alunos, da família e da comunidade escolar em sua totalidade.GESTÃO ESCOLAR DEMOCRÁTICA

A Gestão Escolar Democrática, tem sido alvo de amplas discussões entre os educadores Brasil a fora, essas discussões se referem a este tipo de gestão, por sergarantida na Constituição Federal e na Lei de Diretrizes e Bases da Educação Nacional noo 9394/96, por isso é importante conceituar e caracterizar a Gestão EscolarDemocrática, para que haja elucidação quanto a relevância de ambos na escola.

A palavra "gestão" é originária do latim "gestione", esse conceito de gestão referese à ação e ao efeito de gerir ou de administrar, todavia, ao contrário do que a sociedade pressupõe, a gestão não se refere somente a serviços burocrático, mas sim, humanístico. (ANDRADE, 200I).

A gestão se refere a organização de um conjunto de ações, levando em consideração as demandas espaço escolar e os recursos disponíveis na escola. O gestor escolar tem entre suas obrigações, o ato de planejar, organizar, dirigir e controlar os recursos da escolar onde é diretor, para que os objetivos da educação, sejam alcançados. (GARAY, 20II).

Para Libâneo (2007), a Gestão Escolar Democrática tem como principal característica "as interações sociais que estabelecem entre si e com o contexto sócio-político, nas formas democráticas de tomada de decisões" (p. 324).

O princípio da gestão democrática inclui a participação ativa de todos os professores e da comunidade escolar como um todo, de forma a garantir qualidade para todos os alunos. O processo de gestão deve coordenar a dinâmica do sistema de ensino como um todo. Indo além, discute a importância da articulação das diretrizes e políticas educacionais públicas, e ações para implementação dessas políticas e dos projetos pedagógicos das escolas. (LÜCK, 2007, p. 04). 
Ao se falar em gestão democrática, trata-se de uma administração que preze a democracia, a participação e autonomia da escola, ou seja, trata-se da participação e autonomia da gestão, orientação, supervisão e coordenação dentro da escola.

Para Borges (2004, p. 78) "nas últimas duas décadas têm se observado um movimento de dimensões mundiais rumo a padrões descentralizados de gestão dos sistemas educacionais", isso é muito positivo para a educação, de modo geral.

Essa autonomia, todavia, não se resume apenas a criação de políticas públicas, mas sim na criação de espaços e formas de organização da escola. (BORDIGNON; GRACINDO, 2000).

\section{O PAPEL DO SUPERVISOR EDUCACIONAL NO ESPAÇO ESCOLAR}

O supervisor escolar é o profissional com habilitação em Pedagogia e/ou a nível de especialização, que executa serviços de supervisão e parceria pedagógica na escola, por isso é importante fomentar a importância desse profissional e seu papelna escola.

Ferreira (2017) afirma que o papel do supervisor na escola é "agir, movimentar e envolver-se interagindo na comunidade dos relacionamentos na escola, em sala de aula nas quais os alunos estão inseridos”. (p. I).

É papel do supervisor oferecer assistência ao professor, no que se refere a aprendizagem do aluno, onde ambos trabalham como parceiros político pedagógicos, em uma relação de dependência entre si. (MEDINA, 1997).

O supervisor, tem o papel de atuar como o harmonizador do espaço escolar, uma vez este profissional não atua de forma isolada, tampouco como fiscal do professor, mas sim como um facilitador do trabalho pedagógico.

O supervisor é muito importante para a escola, pois seu papel está relacionado a coordenação das atividades didático-pedagógicas, ao planejamento escolar e ao incentivo coletivo de melhorias contínua no espaço escolar. (PIRES, 200I).

Ainda sobre o papel da supervisão, esta:

[...] deve ser essencialmente a de acompanhar a atualização pedagógica $e$ normativa, com especial atenção, em ambos os casos, aos fundamentos determinados na LDB 9.394/96; propiciar oportunidades de estudo e interlocução aos professores, em atividades coletivas, que reúnam professores que 
desenvolvem um mesmo conteúdo nas diversas séries e níveis escolares; propiciar oportunidades de estudo e decisões coletivas sobre o material didático. (RANGEL, 200I, p. 40).

Ressalta-se, porém, que mesmo o supervisor, sendo um profissional com um papel tão importante para a escola, nem sempre esse papel será reconhecido, valorizado ou até mesmo aceito:

[...] dificilmente a supervisão escolar será totalmente aceita por todos os profissionais da escola, principalmente no que se refere às mudanças, pois muitos profissionais são resistentes às mudanças, no entanto existem possibilidades para eliminar e/ou diluir estas barreiras. (LIMA, 2006, p. o9).

Para Alves (1994), o supervisor também tem o papel de controlar várias ações, pois é encarregado de promover a interação entre teoria e prática, entre pensamentoe ação. Assim sendo, a importância desse profissional na escola é inegável e certamente, pode contribuir para a efetivação de melhorias no sistema de ensino.

\section{AS CONSTRIBUIÇÕES DA ORIENTAÇÃO ESCOLAR EM PARCERIA COM O SUPERVISOR}

O Serviço de Orientação Escolar (SOE) é muito importante para as escolas, pois trata-se, de um profissional que tem o papel de mediar a relação entre professor, aluno, a família e a escola.

A orientação é um processo dinâmico, contínuo, sistemático e integrado emtodo o círculo escolar encarando o aluno como um ser global que deve desenvolver harmoniosamente e equilibradamente todos os aspectos: intelectual, físico, social, moral, estético político educacional e vocacional. (LUCK, 1992, p.64)

Assim sendo, a orientação envolve um trabalho realizado de forma integrada com o supervisor educacional, pois considera o educando e todos os aspectos relacionados a sua cognição, principalmente os aspectos psicológicos, físicos e muitas outras condições.

É papel do orientador também propiciar debates sobre temas relevantes no cotidiano dos alunos, professores e pais, com o objetivo de elevar o nível de cultura da comunidade em que estão inseridos. Quanto à sociedade, este profissional pode discutir com os alunos assuntos comentados pela mídia, pois estes são importantes para o currículo. (PASCOAL, HORONATO E ALBUQUERQUE, 2008, p. o6).

Portanto o orientador escolar, atua como parceiro do supervisor educacional, na construção e desenvolvimento social e cultural do aluno, além de auxiliar os professores na 
mediação da aprendizagem ou nas dificuldades na aquisição de saber.

[...] o papel da orientação educacional é muito significativo, ao possibilitar ao sujeito compreender e analisar esse mundo, compreendendo-se nesta relação com o outro, e também ajudando a escola na interação de suas relações e de seu projeto político pedagógico. (GRINSPUN, 2006, p. 187).

Para Martins (1984) a orientação escolar contribui para a:

[...] formação integral dos educandos (este processo é apreciado em todos os seus aspectos, tido como capaz de aperfeiçoamento e realização), através de conhecimentos científicos e métodos técnicos. A Orientação Educacional é um sistema em que se dá através da relação de ajuda entre Orientador, aluno e demais segmentos da escola. (p. 97).

O orientador escolar é o profissional que faz toda a diferença na superação das dificuldades de aprendizagem, contribuindo para que os alunos "sejam bem-aceitos na escola, na família e na sociedade, circunscrevendo o problema à própria dificuldade de aprendizagem". (COLL, 2004, p. II8).

O orientador pode contribuir de inúmeras formas com a escola, por isso a parceria entre o supervisor e o orientador é muito importante para a escola, afinal unindo essa parceria com o trabalho docente e a aprendizagem do aluno, é possível ter melhores resultados no espaço escolar.

\section{O GESTOR, O ORIENTADOR E O SUPERVISOR COMO PARCEIRO- POLÍTICOPEDAGÓGICO DO PROFESSOR}

O gestor/diretor tem um papel muito importante na atuação do professor no espaço escolar, por isso, é importante que os principais mediadores da educação e aprendizagem escolar, tenham uma relação de parceria política e pedagógica harmoniosa e benéfica para a aprendizagem do educando.

Os professores são a principal voz de uma escola, eles estão na linha de frente do processo ensino/aprendizado, lidando mais diretamente com o aluno. Assim, cabe à direção buscar a excelência na gestão de professores, pois, com professores motivados, ganhos significativos no desempenho acadêmico dos alunos serão percebidos. (OLIVEIRA, 20I8, p. I).

O gestor escolar não deve dificultar o trabalho do professor ou agir como um mero fiscalizador, mas como um intermediário das questões pedagógicas e evitar conflitos que prejudiquem o trabalho docente. 
$\mathrm{Na}$ parceria entre professor e supervisor há posições definidas que indicam o objeto de ação/reflexão para a ação supervisora, a fim de superar impasses conceituais do termo supervisão, compreender a escola como local de trabalho, conceber o professor como um dos trabalhadores da escola e o próprio supervisor identificar-se como trabalhador da escola, desmistificar a figura do supervisor escolar, conceber-se como sujeito que produz e reproduz, pesquisa formas diferentes de aprender, ensinar e orientar, admitirque o professor em sala tem sua própria produção, perceber que é na interação entre professor e aluno que se encontra o eixo principal da aprendizagem na escola. (KELLER, 2009, p. I).

Referente a parceria entre o orientador escolar e o professor, ambos têm o papel de:

[...] refletir sobre o processo educativo que ocorre em sala de aula, identificando aqueles aspectos que necessitam de reflexão. Observa-se, portanto, que o trabalho destes profissionais da educação demanda a aprendizagem da convivência entre as partes, entre as diferenças individuais para criar entre os envolvidos o compromisso na solução de problemas. (LUCION; SILVA; BERTI, 2016, p. 13).

Assim sendo, o gestor, o orientador e o supervisor, devem atuar como parceiros político pedagógico do professor, para que as demandas educacionais da escola, sejam atendidas e para que a relação entre ambos, seja a mais harmônica possível. A escola é um lugar de parceria e essa parceria "requer um objetivo comumindependente de quem são as pessoas ou em que lugar da hierarquia estão”. (LAMB,2019, p. I).

\section{CONCLUSÃO}

O trabalho pedagógico não pode ser realizado de forma isolada na escola, pois todos os profissionais, embora tenham tarefas, papel e responsabilidades diferentes no espaço escolar, são indispensáveis para o funcionamento adequado da escola.

Para que as finalidades da educação sejam atendidas, é preciso que todos os envolvidos no sistema de ensino atuem como parceiros um do outro, afinal, o trabalho de cada profissional estão correlacionados e dependem um com o outro, para que se obtenha o sucesso da atuação na escola.

O gestor escolar, depende do professor para que a escola funcione, e o professor necessita do gestor para manter a escola organizada, mas essa organização do trabalho pedagógico, depende da atuação do supervisor educacional e da atuação do orientador escolar, por isso, cada um desses profissionais, estabelecem uma relação de dependência entre si mesmos. 
O professor precisa ter o supervisor educacional como um parceiro político pedagógico, nas questões relacionadas ao planejamento escolar, execução de projetos de intervenção e apoio pedagógico, ou seja, professor e supervisor caminham juntos e precisam ter uma relação de harmonia e cooperação.

$\mathrm{Na}$ sala de aula, durante o processo de ensino e aprendizagem, o professor se depara com alunos que apresentam múltiplas dificuldades no espaço escolar, e o orientador escolar, atua mediando essas dificuldades e contribuindo para que estas sejam superadas.

Portanto, ficou claro, que não existe nenhum profissional que é melhor que o outro ou dispensável a aprendizagem do aluno e para o funcionamento da escola, todos, seja o gestor, professor, orientador ou o supervisor tem papel relevante e são importantes para que a educação, tenha excelência na escola.

\section{REFERÊNCIAS}

ANDRADE, Belisário H. C. L. Dicionário de sinônimos da língua portuguesa. Elfez,20oI.

ALVES, Nilda. Educação \& Supervisão. São Paulo. Cortez Editora: Autores Associados, 1994.

BORDIGNON, Genuíno; GRACINDO, Regina Vinhaes. Gestão da educação: o município e a escola. In: FERREIRA, Naura Syria Carapeto; AGUIAR, Márcia Ângelada S. (Org.). Gestão da educação: impasses, perspectivas e compromissos. São Paulo: Cortez, 2000. p. $147-176$.

BORGES, André. Lições de reformas da gestão educacional: Brasil, EUA e Grã- Bretanha. São Paulo em Perspectiva, São Paulo, v. I8, n. 3, p. 78-89, jul./set. 2004.

COLL César, MARCHESI Álvaro, PALACIOS Jesus. Desenvolvimento psicológico e educação. Porto Alegre: Artmed, 2004.

FERREIRA, Kelys Christiane Coura Martins. O Papel do Supervisor Escolar. SãoPaulo: Portal Educação, 2017. Disponível em: 〈https://www.portaleducacao.com.br/conteudo/artigos/educacao/opapeldosupervisor -escolar> Acesso em 2i de setembro, 2019, às I6:45. 


\section{$-3$}

GARAY, Ângela. Gestão. In: CATTANI, Antônio David; HOZLMANN, Lorena (Org.).

Dicionário de trabalho e tecnologia. 2. ed. Porto Alegre: Zouk, 20II.

GRINSPUN, Mirian. A Orientação Educacional: conflito de paradigmas e alternativas para a escola. 3.ed. São Paulo: Cortez, 2006.

KELLER, Marcia. A parceria ideal entre o professor e o supervisor escolar. São Paulo: Webartigos, 2009. Disponível em: 〈https://www.webartigos.com/artigos/a- parceriaideal-entre-o-professor-e-o-supervisor-escolar/26207> Acesso em: 21 de setembro, 2019, às 20:39.

LAMB, Joice. Como funciona a parceria entre coordenador pedagógico e orientador educacional. São Paulo: Portal Gestão Escolar, 2019. Disponível em:

<https://gestaoescolar.org.br/conteudo/2115/comofuncionaaparceriaentrecoordenad orpedagogico-e-orientador-educacional $>$ Acesso em 21 de setembro, 2019, às 21:03

LIMA, Elma Correa. Refletindo políticas públicas e educação. In: Supervisão e Orientação Educacional: perspectivas de integração na escola. Cortez Editora, 2006.

LIBÂNEO, José Carlos. A organização e a gestão da escola: teoria e prática.Goiânia: Alternativa, 2007.

LUCK, Heloisa. Gestão educacional: uma questão paradigmática. Petrópolis: Vozes,2007.

LUCK, Heloisa. Planejamento em orientação educacional. Petrópolis: Vozes, I99I.

LUCION; Cibeli; SILVA Richard; BERTI, Vanilda. Estratégias de ação do orientador educacional. Santa Catarina: UNESC, 2016. Disponível em: 〈http://periodicos.unesc.net/criaredu/article/download/294I/2725〉 Acesso em: 2I de setembro, 2019, às 20:48.

MARTINS, José do Prado. Princípios e métodos da orientação educacional. $2^{\underline{a}}$ ed. São Paulo: Atlas, 1984 . 
MEDINA, Antônia da Silva. Supervisão Escolar: da ação exercida à ação repensada. Porto Alegre: EDIPUCRS, 1995.

OLIVEIRA, Maria. Gestão de professores: qual o papel do diretor no desempenho do docente. São Paulo: Portabilis, 2018. Disponível em: 〈https://blog.portabilis.com.br/gestao-de-professores/> Acesso em 21 de setembro, 2019, às 20:27.

PASCOAL, Miriam. HORONATO, Eliane Costa e ALBUQUERQUE, Fabiana aparecida de. O orientador educacional no brasil. Educ. rev. Jun 2008, n⿳o.47, p.roI-I20. Disponível em: 〈http://www.scielo.br/cgi-bin/wxis.exe/iah〉 Acesso em 2I de setembro, 2019, às $16: 45$.

PIRES, Maria Ribeiro. O Papel do Profissional na Escola. In. Revista doDepartamento de Ensino do 2o Grau. SEE/MG, 1990.

RANGEL, Mary. Supervisão Pedagógica: Princípios e práticas. Campinas, SP: Papirus, 200I. 